\title{
Association of maternal CNVs in GSTT1/GSTT2 with smoking, preterm delivery, and low birth weight
}

\author{
Xiaojing Zheng ${ }^{1,2}$, Eleanor Feingold ${ }^{2,3}$, Kelli K. Ryckman ${ }^{4}$, John R. Shaffer ${ }^{3}$, Heather A. Boyd ${ }^{5}$, \\ Bjarke Feenstra $^{5}$, Mads Melbye ${ }^{5}$, Mary L. Marazita ${ }^{6}$, Jeffrey C. Murray ${ }^{4}$ and Karen T. Cuenco ${ }^{3,6 *}$ \\ ${ }^{1}$ Department of Pediatrics, School of Medicine, University of Pittsburgh, Pittsburgh, PA, USA \\ 2 Department of Biostatistics, Graduate School of Public Health, University of Pittsburgh, Pittsburgh, PA, USA \\ ${ }^{3}$ Department of Human Genetics, Graduate School of Public Health, University of Pittsburgh, Pittsburgh, PA, USA \\ ${ }^{4}$ Department of Pediatrics, College of Medicine, University of lowa, lowa City, IA, USA \\ ${ }^{5}$ Department of Epidemiology Research, Statens Serum Institut, Copenhagen, Denmark \\ ${ }^{6}$ Department of Oral Biology, Center for Craniofacial and Dental Genetics, School of Dental Medicine, University of Pittsburgh, Pittsburgh, PA, USA
}

\section{Edited by:}

Rui Feng, University of

Pennsylvania, USA

Reviewed by:

Timothy Thornton, University of Washington, USA

Nathan Wineinger, Scripps

Translational Science Institute, USA

*Correspondence:

Karen T. Cuenco, University of Pittsburgh, 100 Technology Drive, Suite 500, Pittsburgh, PA 15219, USA

e-mail:ktc14@pitt.edu
Preterm delivery (PTD) is an adverse birth outcome associated with increased infant mortality and negative lifelong health consequences. PTD may be the result of interactions between genetics and maternal/fetal environmental factors including smoking exposure (SMK). A common deletion in the GSTT1 gene was previously reported to affect birth outcomes in smokers. In this study, we dissect the associations among SMK, birth outcomes, and copy number variations (CNVs) in the GSTT1/GSTT2 region. A preterm birth case-control dataset of 1937 mothers was part of the GENEVA preterm birth study, which included genome-wide genotyping used to identify CNVs. We examined the association of SMK with birth outcomes, detected CNVs within the GSTT1/GSTT2 region using PennCNV, and examined associations of the identified CNVs with preterm birth and with birth weight (BW) in full term birth controls, including interactions with SMK. Finally, we tested the association of CNVs in GSTT1/GSTT2 with SMK. We confirmed the association of smoking with low BW and PTD. We identified 2 CNVs in GSTT2 (GSTT2 ${ }^{a}$ and GSTT2 ${ }^{b}$ ), 1 CNV in GSTTP1 and 2 CNVs in GSTT1 (GSTT1 $1^{a}$ and GSTT1 $\left.1^{b}\right)$. The GSTT2 $2^{a}$ deletion was associated with reduced BW $(-284 \mathrm{~g}, p=2.50 \mathrm{E}-7)$ in smokers, and was more common in smokers [odds ratio(OR) $=1.30, p=0.04$ ]. We found that the size of the reported common deletion CNV in GSTT1 was larger than previously shown. The GSTTP1 and GSTT1 ${ }^{b}$ null genotypes were in high linkage disequilibrium $(L D)\left(D^{\prime}=0.89\right)$ and less common in smokers $(\mathrm{OR}=0.68, p=0.019$ and $\mathrm{OR}=0.73, p=0.055$, respectively). These two deletions were in partial LD with GSTT2 ${ }^{a}$ and $G S T T 2^{b}$ duplications. All 5 CNVs seem to be associated with increased risk of preterm birth before 35 completed weeks. CNVs in the GSTTT1/GSTT2 region appear associated with low BW and PTD outcomes, but LD complicated these CNVs in GSTT1/GSTT2. In genetic association studies of BW, multiple CNVs in this region need to be investigated instead of a single polymorphism.

Keywords: prematurity, preterm birth, copy number variation, GSTT1, GSTT2, birth weight

\section{INTRODUCTION}

Low birth weight (LBW) refers to the weight of a newborn being less than $2500 \mathrm{~g}$ (Kramer, 1987) and occurs in 16\% of all livebirths worldwide (deOnis et al., 1998). Birth weight is regulated by two major processes: duration of gestation and intrauterine growth rate. Preterm delivery (PTD) of babies born with less than 37 weeks of gestation is responsible for one-third to two-thirds of infants with LBW (Arifeen et al., 2000; Martin et al., 2007). PTD and LBW are independent risk factors for fetal and infant mortality. However, the causes of PTD and LBW are not clear. Multiple factors may contribute to the development of LBW and/or PTD, including genetic and environmental factors, and other specific maternal-fetal characteristics (e.g., demographic, obstetric, nutritional factors, and maternal morbidity during pregnancy) (Kramer, 1987). Based on twin studies, the heritabilites of low birthweight $(<2500 \mathrm{~g})$ and PTD $(<37$ gestational weeks) are estimated to be $37-42$ and $36 \%$, respectively (Clausson et al., 2000).

One of the important environmental factors in birth outcomes is maternal tobacco smoking. Smoking exposure may reduce mean birth weight, and increase the risk of PTD and intrauterine growth restriction (Asmussen and Kjeldsen, 1975; Asmussen, 1977; Nilsen et al., 1984; Ronco et al., 2005; Goldenberg and Culhane, 2007; Haram et al., 2007). Part of the effect of smoking on birth outcomes may be due to the metabolism of the tobacco compound PAH (polycyclic aromatic hydrocarbons) (Perera et al., 2005; Tsui et al., 2008; Wu et al., 2010). PAH is a carcinogenic compound that is detoxified in a two-stage process. PAHs are converted into procarcinogen, which is then conjugated into excretal metabolites. The conjugation is catalyzed 
by the product of the gene GSTT1 (Glutathione S-transferase theta 1), which belongs to the theta class of GSTs. The class members, GSTT1 and GSTT2, are located on human chromosome 22 . The genes are approximately $50 \mathrm{~kb}$ away from each other, with a GSTT pseudo gene (GSTTP1) located between them. GSTT1 and GSTT2 share 55\% amino acid sequence identity and have detoxification roles (Coggan et al., 1998), which make the GSTT1/GSTT2 region an interesting candidate for explaining smoking-induced adverse effects.

A small deletion in GSTT1 is the only reported common copy number variant (CNV) in the region. A null genotype (homozygous deletion) of GSTT1 modifies the effect of maternal smoking on birth outcomes. Smokers have infants with lower mean birth weight compared to non-smokers; however, the reduction varies according to the GSTT1 copy number. Mean birth weight decreases dramatically in smokers with the GSTT1 null genotype compared to smokers with the GSTT1 wild-type genotype (Wang et al., 2002; Wu et al., 2007; Grazuleviciene et al., 2009; AagaardTillery et al., 2010). It is unclear whether other CNVs may exist in the GSTT1/GSTT2 region.

The goal of this study was to explore whether additional CNVs are distributed in GSTT1/GSTT2 and to investigate their associations with smoking and birth outcomes. First, we detected CNVs in the GSTT1/GSTT2 regions. Next, we examined the association of GSTT1/GSTT2 CNVs with birth outcomes, stratifying by smoking status. Finally we investigated the relationship of GSTT1/GSTT2 CNVs with smoking.

\section{MATERIALS AND METHODS STUDY POPULATIONS}

Data were generated as part of the GENEVA (Gene Environment Association studies) preterm birth study (http://www.ncbi.nlm.n ih.gov/projects/gap/cgi-bin/study.cgi?study_id=phs000103.v1.p1) This study is part of dbGAP (http://www.ncbi.nlm.nih.gov/gap) (Mailman et al., 2007). A case-control study of preterm birth identified $\sim 1000$ mother-child case pairs (spontaneous births at $<37$ weeks of gestation), and 1000 mother-child controls pairs (spontaneous births at 40 weeks of gestation) from the Danish National Birth Cohort (DNBC) (Olsen et al., 2001). 1937 mothers had genotype information generated from the Illumina Human660W-Quad chip. Of these, 893 had a preterm birth, 978 delivered at term, and 66 were categorized as neither case nor control (births between 37 and 39 weeks of gestation) and were excluded from the current study. Smoking data came from DNBC prenatal interviews conducted at several points during gestation. For the purposes of this study, we categorized smoking as "any smoking" or "no smoking" during pregnancy.

\section{GENOTYPING AND QUALITY CONTROL}

Complete genotyping and data cleaning reports for the GENEVA preterm birth study are available in dbGAP (https://www. genevastudy.org/sites/www/content/files/datacleaning/data_clean ing_reports/Preterm_Birth_DN_Murray_DCR_9-3-2010.pdf). The genotyping quality was extremely high. For this CNV study, SNPs were not filtered by minor allele frequency or HardyWeinberg equilibrium testing, as those filters tend to remove precisely the SNPs in CNV regions.

\section{CNV CALLS BY PennCNV AND IDENTIFICATION OF CNV REGIONS}

CNV calls for mothers were generated using the PennCNV software and published guidelines (2009Aug27 version) (Wang et al., 2007). A GC wave adjustment option was applied in PennCNV. We removed all samples that had been genome-wide amplified, as CNV calling in such samples is generally poor (Zheng et al., 2012). Samples were then filtered using the criterion log $\mathrm{R}$ ratio standard deviation (LRRSD) $>0.3$ resulting in 1617 out of 1937 mothers eligible for further analysis. All analyses were restricted to autosomes. Human genome build 36 was used for this study. CNVs with copy number $>2$ were defined as duplications, while those with copy number $<2$ were considered deletions. Each $\mathrm{CNV}$ contained at least three consecutive markers. For CNVs with high allele frequency of a deletion, we also applied the PennCNV validation algorithm.

To identify CNV regions between GSTT1 to GSTT2, we first merged CNVs detected by PennCNV if the length of overlap between any two CNVs is greater than $50 \%$ of the size of at least one of the CNVs. The start position of the resulting $\mathrm{CNV}$ region is defined as the minimum base pair position of the overlapping CNVs, and the end position is defined to be the maximum base pair position of the overlapping CNVs.

\section{STATISTICAL ANALYSIS}

We examined the association of smoking with PTD and birth weight in our dataset using logistic and linear regression, respectively. The association of CNVs with birth weight was evaluated using linear regression. Since preterm birth is known to be collinear with birth weight, analyses of birth weight were performed in the controls (full term births) only. The relationship between CNVs and PTD stratified by smoking status was examined using logistic regression. The association between CNVs and smoking adjusted for preterm birth state was assessed using logistic regression.

In regression analysis, deletion CNVs [copy number $(\mathrm{CN})<2$ ] and duplication CNVs $(\mathrm{CN}>2)$ were coded as dummy variables and compared to normal copy number $(C N=2)$, for two separate comparisons. For common deletions (allele frequency of deletion $>35 \%$ ) in GSTT1 and GSTTP1, we compared the homozygous deletions $C N=0$ vs. $C N>0$ as a single dichotomous comparison. We adjusted for infant sex and maternal BMI in all regression models. All calculations were completed in $\mathrm{R}$ (version 2.15.1) (R Development Core Team, 2009). Associations with $p=0.05$ were considered of interest and are reported without additional correction. The linkage disequilibrium (LD) of two CNVs was measured by $D^{\prime}$.

\section{RESULTS}

\section{ASSOCIATION BETWEEN SMOKING AND BIRTH OUTCOMES}

The characteristics of the DNBC/GENEVA mothers by case and control status are described in Table 1 . The average maternal BMI was similar between cases and controls $(p=0.70)$. As expected, the average birth weight in infants of cases was $2463 \mathrm{~g}$, which is significantly lower than in controls $3719 \mathrm{~g}(p<2.20 \mathrm{E}-$ $16)$. The prevalence of smoking reported during pregnancy was significantly higher in cases than in controls (31.4 and $26.2 \%$ respectively, $p=0.029$ ). 
Table 1 | The characteristics of the DNBC/GENEVA mothers (case/control) plus infant birthoutcomes.

\begin{tabular}{llll}
\hline Maternal characteristics & $\begin{array}{l}\text { Cases } \\
\text { (gestational } \\
\text { (weeks < 37) } \\
\mathbf{N = 7 3 6}\end{array}$ & $\begin{array}{l}\text { Controls } \\
\text { (gestational } \\
\text { (weeks = 40) } \\
\mathbf{N = 8 8 1}\end{array}$ & P-value \\
& $2463(650)$ & $3719(459)$ & $<2.20 \mathrm{E}-16$ \\
\hline $\begin{array}{l}\text { Birth weight, mean (SD), g } \\
\text { gestational age, mean (SD), wk }\end{array}$ & $33.9(2.2)$ & $40.0(0)$ & \\
SMOKING DURING PREGNANCY, \% & & \\
$\quad$ No & 68.6 & 73.8 & 0.029 \\
Yes & 31.4 & 26.2 & \\
maternal BMI, mean (SD) & $23.4(4.5)$ & $23.5(4.0)$ & 0.70 \\
INFANT SEX, \% & & & \\
$\quad \begin{array}{l}\text { Male } \\
\text { Female }\end{array}$ & 53.2 & 53.2 & 0.98 \\
\hline
\end{tabular}

$N$, number of mothers; SD, standard deviation; BMI, body mass index; g, grams; wk, weeks.

We conducted association analysis of birth weight in controls (40 weeks gestation) only. Smoking was a significant predictor of birth weight $(p=2.01 \mathrm{E}-10)$. Among the infants with mothers who smoked, the mean birth weight was $277.87 \mathrm{~g}$ lower than in the non-smoking group.

\section{IDENTIFICATION OF CNVs}

Using the methods described above, we found five potential CNV regions located in three genes in the area of GSTT1 GSTT2 (Figure 1). Two CNVs were in GSTT2 (GSTT2 ${ }^{\mathrm{a}}$ and $\left.G S T T 2^{\mathrm{b}}\right)$, one was in GSTTP1, and the remaining two CNVs were in GSTT1 (GSTT1 ${ }^{\mathrm{a}}$ and GSTT1 $\left.{ }^{\mathrm{b}}\right)$. These five CNVs were not independent. The duplications in GSTT2 (GSTT2 ${ }^{\mathrm{a}}$ and $G S T T 2^{\mathrm{b}}$ ) are correlated with two deletions, located in GSTTP1 and GSTT1 $\left(G S T T 1^{\mathrm{b}}\right)$. Detailed information on the relationship among these CNVs is summarized in the Table A1. None of our array markers were located within the GSTT1 null genotype region that has previously been reported in the literature, but our $G S T T 1^{\mathrm{b}}$ region spans that location (see Figure 1), which suggests that the deletion region is larger than previously reported.

\section{ASSOCIATION BETWEEN CNVS IN GSTT1/GSTT2 AND BIRTH WEIGHT}

The 5 CNVs were assessed for association with birth weight in controls (full term births) (Tables 2, 3A,B). The GSTT2 ${ }^{b}$ deletion was the only $\mathrm{CNV}$ associated with birth weight in full term controls (Table 3B, $122.0 \mathrm{~g}, p=0.05$ ). The GSTT2 ${ }^{\mathrm{a}}$ deletion was borderline associated birthweight regardless of smoking status and when examined in solely smokers (Table 3B. in all subjects, $p=0.060$; in smokers only, $p=0.07)$. The $G S T T 2^{\text {b }}$ deletion was also borderline associated with birthweight when looking in non-smokers only (Table $2 ; p=0.09$ among full-term births only). None of the interactions between these five CNVs with smoking were near statistical significance after evaluating a model of birthweight regressed on maternal BMI, infant sex, genotype, and genotype $\mathrm{x}$ smoking status (Table 2, $\left.P_{\text {int }}\right)$.

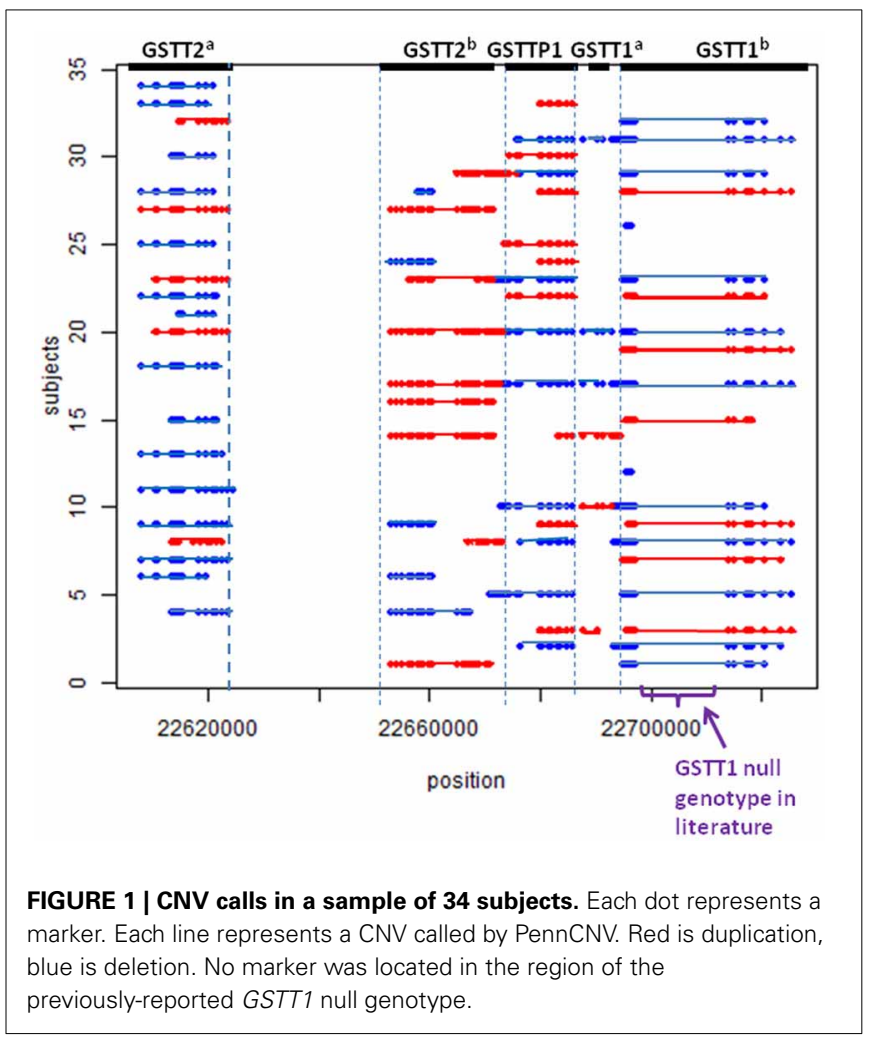

\section{ASSOCIATION BETWEEN CNVS IN GSTTI/GSTT2 AND PRETERM BIRTH}

We then analyzed the association of CNVs with preterm birth (gestational weeks $<37$ ) and with birth $<35$ gestational weeks (Table 2). None of the CNVs were significantly associated with the risk of preterm birth among smoking and non-smoking mothers considered separately (Table 4). However, the GSTT2 ${ }^{\mathrm{a}}$ duplication was borderline significantly associated with an increased risk of birth $<35$ weeks (odds ratio $=1.44, p=$ 0.08 ) in non-smokers (Table 2). Among smokers, the duplication did not significantly influence the risk of birth $<35$ weeks (Table 4; odds ratio $=1.06, p=0.88$ ). The $G S T T 2^{\mathrm{a}}$ deletion was associated with reduced birth weight in full term controls with borderline significance when smoking status was not considered (Table 3B; $-65.3 \mathrm{~g}, p=0.06$ ), but was not associated with preterm birth or birth before 35 weeks (Table 2). Three CNVs [GSTT2 ${ }^{\mathrm{b}}$ duplication (odds ratio = 1.48, $p=0.05$ ), GSTTP1 deletion (odds ratio $=1.38, p=$ 0.09 ) and $G S T T 1^{\mathrm{b}}$ deletion (odds ratio $=1.42, p=0.06$ ) ] were all independently associated or borderline associated with birth $<35$ weeks in non-smokers (Table 2). These three CNVs were also in partial LD with each other. The deletions in GSTTP1 and GSTT1 $^{b}$ are common and the homozygous deletion (null genotypes) frequencies are 15.5 and $15.8 \%$ respectively. The duplication of GSTT2 ${ }^{\mathrm{b}}$ when combined with the effect of smoking was similar to the CNV's effect among nonsmokers (Table 2: odds ratio $=1.86, p=0.05$ ). The deletion of GSTT1 $^{\mathrm{b}}$ was associated with increased risk of birth before 35 weeks (odds ratio $=1.42, p=0.06$ ) in non-smokers and when combined with smoking had comparable effect but was 
Table 2 | Association of CNVs in GSTT1/GSTT2 with birth weight and preterm birth.

\begin{tabular}{|c|c|c|c|c|c|c|c|c|c|c|c|c|}
\hline \multirow[t]{2}{*}{ Outcome } & \multicolumn{5}{|c|}{ Full term birth only (controls) ${ }^{1}$} & \multicolumn{7}{|c|}{ All subjects (cases + controls) ${ }^{2}$} \\
\hline & \multicolumn{5}{|c|}{ Birth weight (g) } & \multicolumn{4}{|c|}{$\begin{array}{c}\text { Preterm Birth } \\
\text { (gestational weeks <37) }\end{array}$} & \multicolumn{3}{|c|}{$\begin{array}{c}\text { Very Preterm }{ }^{3} \text { Birth } \\
\text { (gestational weeks < }<35 \text { ) }\end{array}$} \\
\hline \multicolumn{13}{|c|}{ GENE x SMOKING STATUS COMBINATION } \\
\hline Genotype & Smk & $\mathbf{N}_{1}$ & $\beta(S E)$ & $P$-value & $\mathbf{P}_{\text {int }}^{\#}$ & $\mathbf{N}_{2}$ & Freq $(\%)$ & Odds ratio & $\mathbf{P * *}$-value & Freq (\%) & Odds ratio & $P$-value \\
\hline \multicolumn{13}{|l|}{ GSTT2 $^{a}$} \\
\hline \multirow[t]{2}{*}{ Normal } & - & 375 & Ref & & & 643 & 41.7 & Ref & & 18.8 & Ref & \\
\hline & + & 124 & $-162(47)$ & 5.90E-04 & & 242 & 48.8 & 1.32 & 0.07 & 26.8 & 1.57 & 0.01 \\
\hline \multirow[t]{2}{*}{ Duplication } & - & 89 & $20(53)$ & 0.70 & 0.87 & 162 & 45.1 & 1.15 & 0.45 & 24.7 & 1.44 & 0.08 \\
\hline & + & 23 & -124 (95) & 0.19 & & 50 & 54.0 & 1.55 & 0.13 & 28.0 & 1.68 & 0.12 \\
\hline \multirow[t]{2}{*}{ Deletion } & - & 186 & $-20(41)$ & 0.62 & 0.18 & 311 & 40.2 & 0.91 & 0.49 & 19.3 & 1.04 & 0.81 \\
\hline & + & 84 & $-284(55)$ & $2.50 \mathrm{E}-07$ & & 152 & 44.7 & 1.14 & 0.48 & 20.4 & 1.02 & 0.93 \\
\hline \multicolumn{13}{|l|}{ GSTT $^{b}$} \\
\hline \multirow[t]{2}{*}{ Normal } & - & 512 & Ref & & & 882 & 41.9 & Ref & & 19.3 & Ref & \\
\hline & + & 193 & -199 (38) & $2.55 \mathrm{E}-07$ & & 362 & 46.7 & 1.21 & 0.15 & 24.3 & 1.29 & 0.09 \\
\hline \multirow[t]{2}{*}{ Duplication } & - & 91 & $25(51)$ & 0.62 & 0.45 & 163 & 44.2 & 1.09 & 0.61 & 25.8 & 1.48 & 0.05 \\
\hline & + & 23 & $-90(94)$ & 0.33 & & 51 & 54.9 & 1.67 & 0.08 & 31.4 & 1.86 & 0.05 \\
\hline \multirow[t]{2}{*}{ Deletion } & - & 45 & 117 (69) & 0.09 & 0.68 & 69 & 34.8 & 0.63 & 0.09 & 13.0 & 0.58 & 0.16 \\
\hline & + & 14 & $-141(119)$ & 0.24 & & 29 & 51.7 & 1.47 & 0.31 & 17.2 & 0.85 & 0.74 \\
\hline \multicolumn{13}{|l|}{ GSTTP1 } \\
\hline \multirow[t]{2}{*}{ Present } & - & 544 & Ref & & & 928 & 41.4 & Ref & & 18.8 & Ref & \\
\hline & + & 204 & $-204(37)$ & 6.11E-08 & & 390 & 47.7 & 1.31 & 0.03 & 24.6 & 1.35 & 0.04 \\
\hline \multirow[t]{2}{*}{ Null } & - & 106 & 47 (47) & 0.32 & 0.62 & 188 & 43.6 & 1.11 & 0.53 & 24.6 & 1.38 & 0.09 \\
\hline & + & 27 & -105 (88) & 0.23 & & 54 & 50.0 & 1.31 & 0.35 & 25.9 & 1.48 & 0.24 \\
\hline \multicolumn{13}{|l|}{ GSTT $^{a}$} \\
\hline \multirow[t]{2}{*}{ Normal } & - & 570 & Ref & & & 974 & 41.5 & Ref & & 20.2 & Ref & \\
\hline & + & 199 & $-213(37)$ & 1.27E-08 & & 388 & 48.7 & 1.34 & 0.02 & 25.5 & 1.29 & 0.07 \\
\hline \multirow[t]{2}{*}{ Duplication } & - & 26 & -102 (89) & 0.25 & 0.11 & 51 & 49.0 & 1.23 & 0.46 & 15.7 & 0.62 & 0.26 \\
\hline & + & 13 & $-62(129)$ & 0.63 & & 22 & 40.9 & 1.05 & 0.90 & 18.2 & 0.89 & 0.83 \\
\hline \multirow[t]{2}{*}{ Deletion } & - & 54 & $61(65)$ & 0.34 & 0.87 & 91 & 40.7 & 0.97 & 0.88 & 17.6 & 0.87 & 0.62 \\
\hline & + & 19 & -131 (109) & 0.23 & & 34 & 44.1 & 1.07 & 0.85 & 20.6 & 0.95 & 0.92 \\
\hline \multicolumn{13}{|l|}{ GSTT1 $^{b}$} \\
\hline \multirow[t]{2}{*}{ Present } & - & 543 & Ref & & & 927 & 41.4 & Ref & & 18.7 & Ref & \\
\hline & + & 202 & $-200(37)$ & 1.12E-07 & & 386 & 47.7 & 1.31 & 0.03 & 24.6 & 1.35 & 0.04 \\
\hline \multirow[t]{2}{*}{ Null } & - & 107 & $57(47)$ & 0.23 & 0.83 & 189 & 43.4 & 1.09 & 0.58 & 24.9 & 1.42 & 0.06 \\
\hline & + & 29 & $-121(85)$ & 0.15 & & 58 & 50.0 & 1.32 & 0.33 & 25.9 & 1.48 & 0.22 \\
\hline
\end{tabular}

Marginal effects of CNVs and joint effects of CNV with smoking status reported.

${ }^{1}$ Mothers with full term births. These subjects are known as "controls" and used for the All subjects study sample.

${ }^{2}$ Cases (preterm or very preterm birth mothers) and "controls"3. Research definition of preterm birth.

${ }^{3}$ Ref is the subgroup designated as the referent group for comparison with various CNV subgroups.

${ }^{a}$ and ${ }^{b}$ were used to distinguish different CNVs in the same gene.

Smk is mother reported no smoking (-) or smoking (+) during pregnancy.

$N_{1}$ is the number of mothers with full-term birth only.

$\mathrm{N}_{2}$ is the total number of mothers (cases + controls).

Freq $(\%)$ is the percentage of $N_{2}$ with infant births of either $<37$ or $<35$ gestational weeks.

$\beta$ (SE) is the regression coefficient and standard error estimate for the model under evaluation.

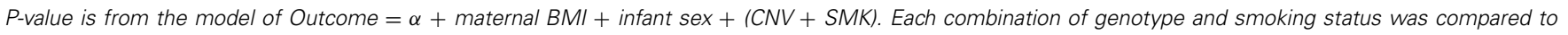
subjects with normal CNV genotype and who were non-smokers.

$P_{\text {int }}$ is the $p$-value for the interaction term in the model is Outcome $=\alpha+$ maternal BMI + infant sex $+S M K+C N V+C N V \times S M K$

not statistically significant as joint risk factors (Table 2. odds ratio $=1.48, p=0.22$ ). The marginal effect in smokers was not significant either (Table 4B: odds ratio $=1.09, p=0.80$ ). The odds ratio for the effect of the GSTTP1 deletion on birth before 35 weeks was similar [Table 2: odds ratio $=1.38$ $(p=0.09)$ and $1.48(p=0.24)$, respectively, in non-smokers and when considered jointly with smoking] to that of the GSTT1 ${ }^{\mathrm{b}}$ deletion.

\section{ASSOCIATION BETWEEN GSTT1/GSTT2 AND SMOKING}

To better understand the relationship among birth outcomes, smoking, and the CNVs we examined, we also tested association 
Table 3 | Effect of CNVs inGSTT1/GSTT2 region on birth weight in full term birth mothers^.

\begin{tabular}{|c|c|c|c|c|c|c|c|c|c|}
\hline \multicolumn{10}{|c|}{ (A) Duplication } \\
\hline \multirow[b]{2}{*}{$\begin{array}{l}\text { Gene } \\
\text { symbol }\end{array}$} & \multirow[b]{2}{*}{$\begin{array}{l}\text { Start } \\
\text { position }\end{array}$} & \multirow[b]{2}{*}{$\begin{array}{l}\text { End } \\
\text { position }\end{array}$} & \multirow[b]{2}{*}{$\begin{array}{l}\text { No. of } \\
\text { SNPs }^{2}\end{array}$} & \multicolumn{2}{|c|}{ All ${ }^{1}$} & \multicolumn{2}{|c|}{ Smokers } & \multicolumn{2}{|c|}{ Non-smokers } \\
\hline & & & & $\begin{array}{l}\text { Change of } \\
\text { mean } \mathrm{BW}^{3}\end{array}$ & $P$-value ${ }^{4}$ & $\begin{array}{l}\text { Change of } \\
\text { mean BW }\end{array}$ & $P$-value & $\begin{array}{l}\text { Change of } \\
\text { mean BW }\end{array}$ & $P$-value \\
\hline GSTT2 $^{\mathrm{a}}$ & 22613516 & 22623656 & 11 & 25.1 & 0.60 & 38.09 & 0.71 & 12.2 & 0.82 \\
\hline GSTT2 $^{b}$ & 22653131 & 22671429 & 30 & 45.5 & 0.32 & 98.31 & 0.33 & 13.9 & 0.78 \\
\hline GSTTP1 & 22679906 & 22685981 & 10 & - & & & - & - & - \\
\hline GSTT1 ${ }^{a}$ & 22693154 & 22694601 & 17 & -51.5 & 0.50 & 122.58 & 0.35 & -113.8 & 0.20 \\
\hline GSTT1 ${ }^{\mathrm{b}}$ & 22695592 & 22723364 & 23 & - & & & - & - & - \\
\hline
\end{tabular}

(B) Deletion

\begin{tabular}{|c|c|c|c|c|c|c|c|c|c|}
\hline \multirow[b]{2}{*}{$\begin{array}{l}\text { Gene } \\
\text { symbol }\end{array}$} & \multirow[b]{2}{*}{$\begin{array}{l}\text { Start } \\
\text { position }\end{array}$} & \multirow[b]{2}{*}{$\begin{array}{l}\text { End } \\
\text { position }\end{array}$} & \multirow[b]{2}{*}{$\begin{array}{l}\text { No. of } \\
\text { SNPs }\end{array}$} & \multicolumn{2}{|c|}{ All } & \multicolumn{2}{|c|}{ Smokers } & \multicolumn{2}{|c|}{ Non-smokers } \\
\hline & & & & $\begin{array}{l}\text { Change of } \\
\text { mean BW }\end{array}$ & $P$-value & $\begin{array}{l}\text { Change of } \\
\text { mean BW }\end{array}$ & $P$-value & $\begin{array}{l}\text { Change of } \\
\text { mean BW }\end{array}$ & $P$-value \\
\hline GSTT2 ${ }^{\mathrm{a}}$ & 22613516 & 22623656 & 11 & -65.3 & 0.06 & -116.8 & 0.07 & -24.9 & 0.54 \\
\hline GSTT2 $^{\mathrm{b}}$ & 22653131 & 22671429 & 30 & 122.0 & 0.05 & 91.1 & 0.47 & 120.2 & 0.08 \\
\hline GSTTP1 & 22679906 & 22685981 & 10 & 66.7 & 0.12 & 92.1 & 0.33 & 41.1 & 0.39 \\
\hline GSTT1 a & 22693154 & 22694601 & 17 & 80.3 & 0.15 & 33.4 & 0.76 & 97.4 & 0.13 \\
\hline GSTT1 ${ }^{\mathrm{b}}$ & 22695592 & 22723364 & 23 & 68.6 & 0.11 & 79.8 & 0.38 & 49.7 & 0.29 \\
\hline
\end{tabular}

Duplication (A) and deletion (B) effects.

$\wedge$ "Full term birth mothers" are designated "controls" elsewhere.

1 "All" consists of Smoker and Non-smoker mothers combined.

2 "No. of SNPS" is the number of SNPS typed within the region defined by start and end positions.

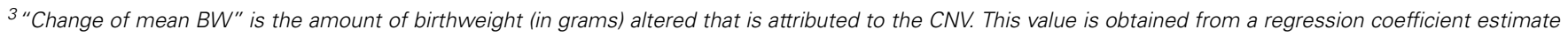
for the CNV in the model while adjusting for maternal body mass index and infant sex.

"P-value" is the p-value associated with change of mean BW.

-No estimate obtained.

between the CNVs and smoking. Our examination of the relationship between smoking and GSTT1/GSTT2 CNVs while adjusting for birth weight indicated that the duplication CNVs were not significantly associated with smoking. However, the deletion CNV in GSTT2 $2^{\mathrm{a}}$ was significantly associated with smoking (Table 5. odds ratio of smoking vs. non-smoking in carriers of this deletion $=1.30, p=0.04$ ). This same deletion and smoking were jointly associated with decreased birth weight (Table 2; $-284 \mathrm{~g}, p=2.50 \times 10 \mathrm{E}-07$ ), but the deletion alone accounted for less than half of the decreased weight (Table 3B. $-116.8 \mathrm{~g}, p=$ $0.07)$ in smokers. Smokers were also less likely to have the deletions in GSTTP1 and GSTT1 ${ }^{\mathrm{b}}$ (Table 5: odds ratios $=0.68(p=$ $0.02)$ and $0.73(p=0.06)$, respectively). These deletions tend to increase birth weight in controls, although not significantly (Table 2).

\section{DISCUSSION}

Linkage and SNP association studies have identified some genetic factors that are associated with adverse birth outcomes, including GSTT1. However, few CNV studies have been conducted for LBW and PTD outcomes. We focused on examining CNVs in the region from GSTT1 to GSTT2 and investigating their association with adverse birth outcomes and smoking.
Our finding that smoking may be associated both preterm birth and birth weight is consistent with other reports (Horta et al., 1997; Chan et al., 2001).

After identifying five CNV regions in GSTT2, GSTTP1, and GSTT1, we noted the complex association patterns with preterm birth and birth weight, which may be related to LD among the CNVs. The GSTT2 duplications GSTT2 $2^{a}$ and GSTT2 $2^{b}$ ), GSTTP1 deletion and GSTT1 ${ }^{\mathrm{b}}$ deletion are in partial LD (see Table A1). The GSTT2 $2^{a}$ deletion decreased the mean birth weight in infants of smoking mothers and is more likely to be present in smokers, but the weight change was of borderline statistical significance. In contrast, the $G S T T 2^{b}$ deletion increases the birth weight (Table 3B: $120.2 \mathrm{~g}, p=0.08$ ) in infants of non-smoking mothers and is more common in non-smokers (Table 5: odds ratio of smoking vs. non-smoking $=0.68, p=0.20$ ), but again the weight change was of borderline statistical significance. Interestingly, neither of the GSTT2 deletions was associated with preterm birth or "very preterm" birth (<35 weeks) (Windham et al., 2000; Danileviciute et al., 2012), but both GSTT2 duplications appear to be associated with increased risk of birth before 35 weeks in nonsmokers, and associated with an even higher risk when smoking and the duplications were considered jointly. These findings suggest that GSTT2 may have a role in detoxification of tobacco, although it is also possible that these results are explained by LD 


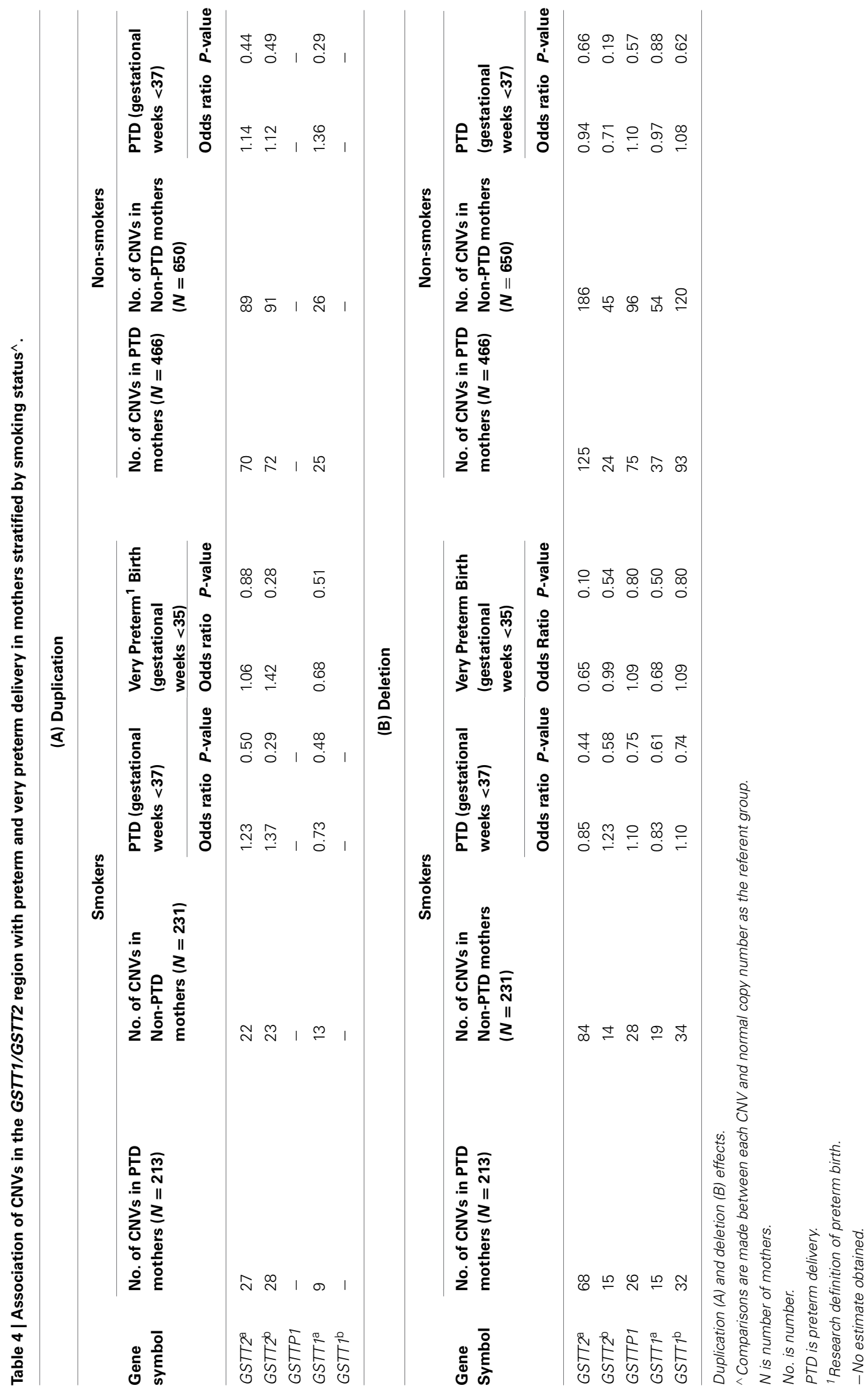


Table 5 | Association of CNVs in the region from GSTT1/GSTT2 region with smoking^.

\begin{tabular}{|c|c|c|c|c|c|c|}
\hline \multirow[b]{2}{*}{$\begin{array}{l}\text { Gene } \\
\text { symbol }\end{array}$} & \multirow[b]{2}{*}{$\begin{array}{l}\text { Start } \\
\text { position }\end{array}$} & \multirow[b]{2}{*}{$\begin{array}{l}\text { End } \\
\text { position }\end{array}$} & \multicolumn{2}{|c|}{ Duplication } & \multicolumn{2}{|c|}{ Deletion } \\
\hline & & & $\begin{array}{l}\text { Odds } \\
\text { ratio }\end{array}$ & $P$-value & $\begin{array}{l}\text { Odds } \\
\text { ratio }\end{array}$ & $P$-value \\
\hline GSTT2 $^{\mathrm{a}}$ & 22613516 & 22623656 & 0.82 & 0.27 & 1.30 & 0.04 \\
\hline GSTT2 $^{\mathrm{b}}$ & 22653131 & 22671429 & 0.77 & 0.12 & 0.68 & 0.20 \\
\hline GSTTP1 & 22679906 & 22685981 & - & - & 0.68 & 0.02 \\
\hline GSTT1 & 22693154 & 22694601 & 1.08 & 0.76 & 0.94 & 0.76 \\
\hline GSTT $1^{\mathrm{b}}$ & 22695592 & 22723364 & - & - & 0.73 & 0.06 \\
\hline
\end{tabular}

${ }^{\wedge}$ Comparison of $\mathrm{CNV}$ with smoking status adjusting for birth weight.

-No estimate obtained.

with other polymorphisms or multiple testing effects. CNVs in GSTT2 may influence the metabolism of nicotine, and exacerbate the toxic effects of smoking.

The deletions in GSTTP1 were in high LD with $G S T T 1^{b}$ $(22,695,592-22,725,333 \mathrm{bp})\left(D^{\prime}=0.89\right)$ and in moderate $\mathrm{LD}$ with two duplications in GSTT2 $\left(D^{\prime}=0.62\right)$. We did not observe significant effects of GSTTP1 and GSTT1 ${ }^{b}$ deletions on birth weight in full term controls, but they were associated with increased risk of birth before 35 weeks in both non-smokers and smokers, with the odds ratio slightly higher when the deletions were considered jointly with smokers. This suggests that GSTTP1 and GSTT1 $1^{\mathrm{b}}$ deletions are associated with reduced birth weight through very preterm birth, but the effect on birth weight was not detected when including full term infants. We also found that GSTTP1 and $G S T T 1^{b}$ deletions were less likely to occur in smokers. Smoking could be a proxy for some other linked yet unknown behavior or may be independently associated with these deletion CNVs.

We compared our CNV results in GSTT1 and GSTT2 with published findings for the previously described GSTT1 CNV, which was reported to modify the effect of smoking on birth weight (Wang et al., 2002; Wu et al., 2007; Grazuleviciene et al., 2009; Aagaard-Tillery et al., 2010). Smokers with the null genotype of GSTT1 had infants with lower mean birth weight than those with the wildtype genotype of GSTT1. The deletion's physical genomic position (22,698,742-22,706,887 bp on chromosome 22) was not covered by the HumanHap660 chip resulting in a marker gap between 22,697,104, and 22,713,954 bp in our arrays. However, our GSTT1 ${ }^{\mathrm{b}}$ deletion encompasses the reported GSTT1 null genotype region. It is notable that the frequency of the homozygous $G S T T 1^{b}$ deletion CNV in our data was highly consistent with the previously reported frequency of the GSTT1 null genotype in Denmark (15\%) (Saadat et al., 2001). In contrast to most previous studies, we were able to examine the influence of $G S T T 1^{a}$ and $G S T T 1^{b}$ deletions on fetal growth in women with full term births, which means that we were able to examine the effects on birth weight more or less independently of effects on gestational age. We did not find significant association of GSTT1 deletions with birth weight in full term birth, nor did we observe interactions of genotypes and smoking status on birth weight in controls. This may be due to the relatively small number of mothers who smoked during pregnancy, or due to the smoking measurement being a dichotomous measure. When contrasted with earlier reports of a GSTT1 — smoking interaction impacting birth outcomes, the current study's lack of evidence for an interaction may be attributed to differences in confounders included in models, variability of smoker definitions, and this study's mothers being categorized as non-smokers based on the pregnancy time period only.

A single SNP (rs1622002) in GSTT2 has been associated with metabolism of major tobacco carcinogen PAH (Wang et al., 2008), but this SNP was not included in the present study's genotype panel.

There are several epidemiologic limitations in our study. Smoking was recorded as any smoking present during pregnancy, which did not consider the influence of smoking in different trimesters. Secondly, regressions were adjusted for some demographic factors, but excluded adjustments for psychosocial factors. Statistical evaluations were not corrected for multiple testing which tempers the conclusions that can be drawn about associations, but the uncorrected $p$-values do suggest a prioritization of findings to pursue in future studies.

In addition to the epidemiological issues, $\mathrm{CNV}$ calls are notoriously error-prone. It is not feasible to validate specific CNV calls within the context of a large-scale association study. However, for any given $\mathrm{CNV}$ with calling error rates independent of phenotype, those errors should only reduce power and not cause bias in the association measure (Zheng et al., 2012). We have no reason to expect CNV calling biases in the current study, so we feel that our results are quite robust. Moreover, the fact that our frequency for the GSTT1 $^{b}$ homozygous deletion was an almost perfect match to the frequency reported in this population for the known deletion was very reassuring. We did not compare our PennCNV CNV calls to any other algorithm in this study, although we did so previously in a more explicit algorithm comparison (Zheng et al., 2012).

Despite these limitations, our study is able to shed light on CNVs in smoking-associated adverse birth outcomes. Our candidate gene analysis in GSTT1/GSTT2 and identification of five CNVs that appear to be associated with birth weight and/or birth before 35 weeks is novel. The distribution and LD pattern of these CNVs are more complicated than expected, which may impact our understanding of the relationship between the GSTT1 deletion and adverse birth outcomes. Follow-up genetic association studies of birth weight need to include multiple CNVs in this region instead of single polymorphisms. Additional studies including molecular evidence will be needed to validate the detected CNVs and replicate these results.

\section{ACKNOWLEDGMENTS}

We thank the preterm birth subjects for their participation in this study. These subjects were a part of the Danish National Birth Cohort (DNBC), which was established with the support of a major grant from the Danish National Research Foundation. Additional support for the DNBC has been provided by the Danish Pharmacist's Fund, the Egmont Foundation, the March of Dimes Birth Defects Foundation, the Augustinus Foundation, and the Health Fund of the Danish Health Insurance Societies. We also thank Johns Hopkins University Center for Inherited Disease Research (CIDR), Baltimore, MD, USA for conducting the genotyping. The genotyping was supported by U01HG004438-01 NIH 
GEI grant "JH/CIDR Genotyping for Genome-Wide Association Studies," National Human Genome Research Institute, National Institutes of Health, Bethesda, MD, USA. This study was also supported by funding through NIH HD-004423-01 "Genome-wide

\section{REFERENCES}

Aagaard-Tillery, K., Spong, C. Y., Thom, E., Sibai, B., Wendel, G. Jr., Wenstrom, K., et al. (2010). Pharmacogenomics of maternal tobacco use: metabolic gene polymorphisms and risk of adverse pregnancy outcomes. Obstet. Gynecol. 115, 568-577. doi: 10.1097/AOG.0b013e3181d06faf

Arifeen, S. E., Black, R. E., Caulfield, L. E., Antelman, G., Baqui, A. H., Nahar, Q., et al. (2000). Infant growth patterns in the slums of Dhaka in relation to birth weight, intrauterine growth retardation, and prematurity. Am. J. Clin. Nutr. 72, 1010-1017.

Asmussen, I. (1977). Ultrastructure of the human placenta at term. Observations on placentas from newborn children of smoking and non-smoking mothers. Acta Obstet. Gynecol. Scand. 56, 119-126. doi: $10.3109 / 00016347709158353$

Asmussen, I., and Kjeldsen, K. (1975). Intimal ultrastructure of human umbilical arteries. Observations on arteries from newborn children of smoking and nonsmoking mothers. Circ. Res. 36, 579-589. doi: 10.1161/01.RES.36.5.579

Chan, A., Keane, R. J., and Robinson, J. S. (2001). The contribution of maternal smoking to preterm birth, small for gestational age and lowbirthweight among Aboriginal and non-Aboriginal births in South Australia. Med. J. Aust. 174, 389-393.

Clausson, B., Lichtenstein, P., and Cnattingius, S. (2000). Genetic influence on birthweight and gestational length determined by studies in offspring of twins. BJOG 107, 375-381. doi: 10.1111/j.14710528.2000.tb13234.x

Coggan, M., Whitbread, L., Whittington, A., and Board, P. (1998). Structure and organization of the human theta-class glutathione S-transferase and D-dopachrometautomerase gene complex. Biochem. J. 334(Pt 3), 617-623.

Danileviciute, A., Grazuleviciene, R., Paulauskas, A., Nadisauskiene, R., and Nieuwenhuijsen, M. J. (2012). Low level maternal smoking and infant birthweight reduction: genetic contributions of GSTT1 and GSTM1 polymorphisms. BMC Pregnancy Childbirth 12:161. doi: 10.1186/1471-2393-12-161
deOnis, M., Blössner, M., and Villar, J. (1998). Levels and patterns of intrauterine growth retardation in developing countries. Eur. J. Clin. Nutr. 52(Suppl. 1), S5-S15.

Goldenberg, R. L., and Culhane, J. F. (2007). Low birth weight in the United States. Am. J. Clin. Nutr. 85, 584S-590S.

Grazuleviciene, R., Danileviciute, A., Nadisauskiene, R., and Vencloviene, J. (2009). Maternal smoking, GSTM1 and GSTT1 polymorphism and susceptibility to adverse pregnancy outcomes. Int. J. Environ. Res. Public Health 6, 1282-1297. doi: 10.3390/ijerph6031282

Haram, K., Svendsen, E., and Myking, O. (2007). Growth restriction: etiology, maternal and neonatal outcome. A review. Curr. Women's Health Rev. 3, 145-160. doi: $10.2174 / 157340407781387690$

Horta, B. L., Victora, C. G., Menezes, A. M., Halpern, R., and Barros, F. C. (1997). Lowbirthweight, pretermbirths and intrauterine growth retardation in relation to maternalsmoking. Paediatr. Perinat. Epidemiol. 11, 140-151. doi: 10.1046/j.1365-3016.1997.d01-17.x

Kramer, M. S. (1987). Intrauterine growth and gestation determinants. Pediatrics 80, 502-511.

Mailman, M. D., Feolo, M., Jin, Y., Kimura, M., Tryka, K., Bagoutdinov, R., et al. (2007). The NCBI dbGaP database of genotypes and phenotypes. Nat. Genet. 39, 1181-1186. doi: 10.1038/ng1007-1181

Martin, J. A., Hamilton, B. E., Sutton, P. D., Ventura, S. J., Menacker, F., Kirmeyer, S., et al. (2007). Births: final data for 2005. Natl. Vital Stat. Rep. 56, 1-103.

Nilsen, S. T., Sagen, N., Kim, H. C., and Bergsiø, P. (1984). Smoking, hemoglobin levels, and birth weights in normal pregnancies. Am. J. Obstet. Gynecol. 148, 752-758.

Olsen, J., Melbye, M., Olsen, S. F., Sørensen, T. I., Aaby, P., Andersen, A. M., et al. (2001). The danish national birth cohort. Its background, structure and aim. Scand. J. Public Health 29, 300-307. doi: 10.1177/14034948010290040201

Perera, F. P., Tang, D., Rauh, V., Lester, K., Tsai, W. Y., Tu, Y. H., et al. (2005). Relationships among polycyclic aromatic hydrocarbonDNA adducts, proximity to the World Trade Center, and effects

Association Studies of Prematurity and Its Complications" and NIH HD-052953 "Identification of Maternal and Fetal Genetic Factors in Preterm Birth," National Institutes of Health, Bethesda, MD, USA. The work of XZ was supported by T32MH095169.

on fetal growth. Environ. Health Perspect. 113, 1062-1067. doi: 10.1289/ehp.7908

R Development Core Team. (2009). R: A Language and Environment for Statistical Computing. R Foundation for Statistical Computing. Vienna. Available online at: http://www.Rproject.org

Ronco, A. M., Arguello, G., Munoz, L., Gras, N., and Llanos, M. (2005). Metals content in placentas from moderate cigarette consumers: correlation with newborn birth weight. Biometals 18, 233-241. doi: 10.1007/s10534-005-0583-2

Saadat, M., Farhud, D. D., and Saadat, I. (2001). Frequency of Glutathione S-transferase M1 (GSTM1) and GSTT1 null genotypes in fars population (South of Iran). Iran. J. Public Health 30, 83-86.

Tsui, H. C., Wu, H. D., Lin, C. J., Wang, R. Y., Chiu, H. T., Cheng, Y. C., et al. (2008). Prenatal smoking exposure and neonatal DNA damage in relation to birth outcomes. Pediatr. Res. 64, 131-134. doi: 10.1203/PDR.0b013e3181799535

Wang, K., Li, M., Hadley, D., Liu, R., Glessner, J., Grant, S. F., et al. (2007). PennCNV: an integrated hidden Markov model designed for high-resolution copy number variation detection in wholegenome SNP genotyping data. Genome Res. 17, 1665-1674. doi: 10.1101/gr.6861907

Wang, S., Chanock, S., Tang, D., Li, Z. Jedrychowski, W., and Perera, F. P. (2008). Assessment of interactions between PAH exposure and genetic polymorphisms on PAH-DNA adducts in African American, Dominican, and Caucasian mothers and newborns. Cancer Epidemiol. Biomarkers Prev. 17 405-413. doi: 10.1158/1055-9965. EPI-07-0695

Wang, X., Zuckerman, B., Pearson, C., Kaufman, G., Chen, C., Wang, G., et al. (2002). Maternal cigarette smoking, metabolic gene polymorphism, and infant birth weight. JAMA 287, 195-202. doi: 10.1001/jama.287.2.195

Windham, G. C., Hopkins, B. Fenster, L., and Swan, S. H. (2000). Prenatal active or passive tobacco smoke exposure and the risk of preterm delivery or low birth weight. Epidemiology 11, 427-433. doi: 10.1097/00001648-20000700000011
Wu, F. Y., Wu, H. D., Yang, H. L., Kuo, H. W., Ying, J. C., Lin, C. J., et al. (2007). Associations among genetic susceptibility, DNA damage, and pregnancy outcomes of expectant mothers exposed to environmental tobacco smoke. Sci. Total Environ. 386, 124-133. doi: 10.1016/j.scitotenv. 2007.06.003

Wu, J., Hou, H., Ritz, B., and Chen, Y. (2010). Exposure to polycyclic aromatic hydrocarbons and missed abortion in early pregnancy in a Chinese population. Sci. Total Environ.. 408, 2312-2318. doi: 10.1016/j.scitotenv. 2010.02.028

Zheng, X., Shaffer, J. R., McHugh, C. P., Laurie, C., Melbye, M., Murray, J. C., et al. (2012). Using family data as a verification standard to evaluate $\mathrm{CNV}$ calling strategies for genetic association studies. Genet. Epidemiol. 36, 253-262. doi: 10.1002/gepi.21618

Conflict of Interest Statement: The authors declare that the research was conducted in the absence of any commercial or financial relationships that could be construed as a potential conflict of interest.

Received: 30 June 2013; accepted: 16 September 2013; published online: 28 October 2013.

Citation: Zheng X, Feingold E, Ryckman KK, Shaffer JR, Boyd HA, Feenstra B, Melbye M, Marazita ML, Murray JC and Cuenco KT (2013) Association of maternal CNVs in GSTT1/GSTT2 with smoking, preterm delivery, and low birth weight. Front. Genet. 4:196. doi: 10.3389/fgene.2013.00196

This article was submitted to Statistical Genetics and Methodology, a section of the journal Frontiers in Genetics.

Copyright (c) 2013 Zheng, Feingold, Ryckman, Shaffer, Boyd, Feenstra, Melbye, Marazita, Murray and Cuenco. This is an open-access article distributed under the terms of the Creative Commons Attribution License (CC BY). The use, distribution or reproduction in other forums is permitted, provided the original author(s) or licensor are credited and that the original publication in this journal is cited, in accordance with accepted academic practice. No use, distribution or reproduction is permitted which does not comply with these terms. 


\section{APPENDIX}

Table A1 | Cross-tabulation and linkage disequilibrium of CNVs in GSTT1/GSTT2 region. Duplication (Dup) or deletion (Del) is present $(+)$ or absent (-).

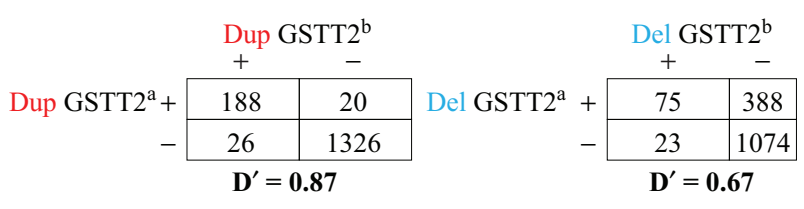

$$
\text { Del GSTT2 }{ }^{\text {b }}
$$$$
\text { Dup GSTT2 }{ }^{\mathrm{b}}
$$

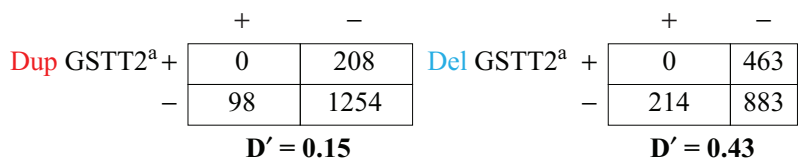

Del GSTTP1

Del GSTTP1

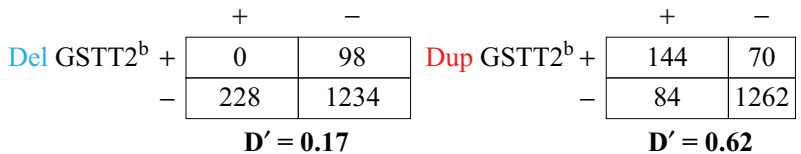

$$
\text { Del GSTT1 }{ }^{\text {b }}
$$

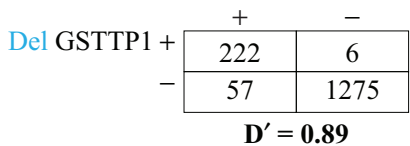

